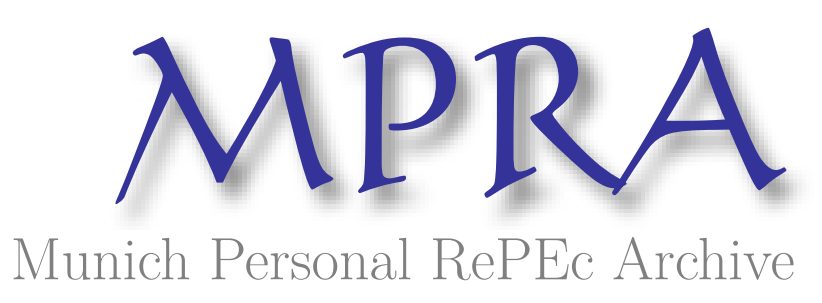

A Partner in Crime: Assortative
Matching and Bias in the Crime Market

Gavrilova, Evelina

University of Turin

1 October 2013

Online at https://mpra.ub.uni-muenchen.de/50432/

MPRA Paper No. 50432, posted 06 Oct 2013 12:20 UTC 


\title{
A Partner in Crime: Assortative Matching and Bias in the Crime Market*
}

\author{
Evelina Gavrilova \\ University of Turin
}

October 2, 2013

\begin{abstract}
In this paper I analyze partnership formation within the property crime market in the United States. I develop a static matching model, in which a criminal forms a partnership with a counterpart with the same probability of success. Using individual arrest data from the National Incident Based Reporting System, I pinpoint matches where the underlying ability of two partners differ. This difference in ability is correlated to observable characteristics, making the case for discrimination. By comparing the regression results to success means for the same demographic groups, I find patterns consistent with discrimination. Beside the patterns of gender and racial segregation, I find that in white-black matches, blacks outperform whites, consistent with success means. In male-female matches the female's success realization is higher than the male's, contrary to the difference in success means, where males on average outperform females, hinting at a distaste premium.
\end{abstract}

Keywords: Organized Crime, Assortative Matching, Discrimination JEL Codes: K42, J16, J71, C78

*I am grateful to Giovanni Mastrobuoni and Floris Zoutman for thorough comments. I also thank seminar participants at the University of Essex and Erasmus University Rotterdam. This paper has been also presented at the Lyon-Turin Doctoral workshop. The usual disclaimer applies. I am proud to cite 3 different influential works by Gary Becker in the first sentence. 


\section{Introduction}

When a criminal wants to commit to a partnership, just like two spouses commit in a marriage, she would have to choose a partner by her looks. (Becker, 1957, 1968, 1973). Organizing a crime together allows criminals to commit more sophisticated acts than they would on their own and, given that more people think on how to cover their traces, a group can prove to be more elusive to law-enforcement than a single criminal. If the commission of crime was like a marriage (or vice versa), then each partner would prefer to match with a more successful counterpart, that would guarantee better outcomes. In my setting, in equilibrium criminals prefer an associate with the same criminal ability as their own. This allows me to determine when partner choice is correlated to her observable traits, as an application of discrimination.

The choice of a marriage partner often follows a pattern of positive assortative matching, where highly educated partners prefer to marry their peers (for e.g. Rose (2007)) and partners with high earnings potential select one another(for e.g. Pencavel (1998), Nakosteen et al. (2004)). In the context of offending, this means selecting a smart partner, who would not snitch and who would take care of the extra corpses. Until now the economic literature on crime has focused on single offenders (Becker, 1968) and big organized groups. This paper is the first to consider the building of a small group, applying the theory of assortative matching to small criminal enterprises. While discrimination in the presence of assortative matching has been explored in the context of employer-employee matches (for e.g. Borowczyk-Martins et al. (2012),Flabbi $(2010)$ ), the crime market offers a unique facet that reveals the underlying ability, namely arrest, allowing for a measure of the match quality in the presence of discriminating biases.

In the real criminal world, the practice of the police offering a bargain to the offender that was first apprehended in order to catch his partner creates an incentive to choose one's partner as the best from all possible candidates. Therefore, I model matches by assuming that the desired partner trait is a high ability to escape law-enforcement. This incentive leads both partners to desire a successful counterpart, thereby creating a pattern of positive assortative matching between criminals.

Using individual data on criminals from the National Incident Based Reporting System (NIBRS), I find patterns of gender and race segregation that lend me the result of non-random matching. Furthermore, criminals most often prefer a partner from their own gender and race, consistent with criminological evidence on trust issues being resolved by connecting along social and blood ties (for e.g. Alarid et al. (2009)).

Arguably, an arrest reveals whether a criminal is of high or low ability. Given the positive assortative matching, the two partners should be of the same ability level and empirically this would be the case if both of them got arrested or both of them run free. If only one partner gets arrested, then there could be an ability difference between the partners. If this difference turns out to be systematically correlated to observables, then there is a bias in matching. For example, if in a black-white pair the whites always gets arrested, then their ability level was overestimated by the blacks, hinting at a prejudice or bias, based on the skin colour. In other words, I set the counter factual productivity difference between the partners to 0 due to the matching incentive, and consider any systematic 
difference as taste bias.

To illustrate my empirical strategy I turn to a simple frictionless model of taste discrimination. My model differs with previous treatments of taste discrimination, as I consider a taste bias to be exercised at the scale of a demographic group, that is, each member of one group is biased against a member of the other group. The benchmark matching is unbiased when a criminal matches with a partner of his same ability level. Turning to biases, a negative taste has to be compensated by a partner's ability level higher than the one of the person exercising the taste. Similarly, a positive taste allows one to match with a partner with a lower ability level than his own. Looking at interactions between the tastes of the groups, one group could have a high negative taste when matching with another group, resulting in no matches between the 2 groups and segregation. However, full segregation is not observed in the data and I concentrate on between group matches. Two groups are compatible and form matches between one another either if both have positive tastes, or when one group has a negative taste compensated by the positive one of the other group. In both cases there are multiple Nash Equilibria for matching choices. Therefore, in this framework, finding evidence of taste bias can be a necessary but not a sufficient condition to claim that such preferences are exercised. The bias would be apparent whenever the difference in ability between partners is correlated to the observable characteristic that defines a demographic group.

On the individual level, the arrest of one's partner is more likely to seem as an act of policing than as a group common act of poor judgment of blacks with respect to whites. I find that in black-white partnership, most often than not the whites turn out to be of poor quality and face on average a lower probability of success, both as a group and as partners of successful blacks. Given that they have been chosen on the base of their ability, there must be a systematic taste component to the choice, that makes black criminals desire white counterparts. When considering genders, on average males are more successful than females. However, in male female partnerships the females are of higher criminal ability than the males. Therefore, females overvalue the ability of males, consistent with a positive taste preference, which might underline a negative taste that males exercise with respect to females.

From all other probable reasons for these patterns, several can be rejected right away. First, if one partner perceives an act specific advantage (for e.g. that a white partner would be more likely to blend into the neighborhood where the crime act is committed), this is individually specific for one crime and cannot be systematic for all the 900 thousand partnerships in the sample. Second, if there is only one partner of a certain demographic group in the market, then he could match favorably. Even if this is a (unreasonable) systematic occurrence, in my analysis I can control for the diversity of the criminal population and my results hold even when considering only markets with heterogeneous population. Third, females might be assigned the safer role in the commission of the crime because of gender stereotypes, and thus they have a higher success probability. This cannot hold true for black-white male couples, any choice frictions would be individual crime specific, controlling for individual offenses does not change the results and nothing hinders the male to turn the female in and thus contribute to a lower aggregate success probability. Even when I control for measurement errors by taking a subsample where only arrested couples are the control group and a subsample of daylight crimes, results remain robust. Only when I consider 
criminals whose age is known and above 30, I find evidence that the bias for females has disappeared, hinting at an explanation of statistical discrimination with respect to gender.

This paper links the notion of assortative matching to similarity in observables, as currently studied with network theory. The preference-for-same has been documented in diverse settings. Bagues \& Perez-Villadoniga (2012) show in a natural experiment that recruiters prefer applicants who have similar to their's skills. Arcand \& Fafchamps (2012) demonstrate assortative matching in social traits like ethnic proximity and wealth between members in communitybased organizations in developing countries. While the 2 notions are used interchangeably in some contexts, here they can be treated separately. I show explicitly that matching on observables conflicts with matching on ability.

By the virtue of arrest data, I can link assortative matching and similarity of observables to a productivity measure, thus detecting discrimination. The economic notion of discrimination has been developed by Becker (1957), and Aigner \& Cain (1977) provide formal treatment to the concepts of taste and statistical discrimination. Interested readers might refer to Lang \& Lehmann (2012) for an up-to-date discussion of the literature. Structural work on search has explored discrimination. Particularly, Borowczyk-Martins et al. (2012) and Flabbi (2010) are examples of a search model describing patterns of matching and racial wage gaps in the light of taste discrimination. The setting in my paper differs, I provide a frictionless model of matching and take a reduced form empirical approach.

There are 2 sides to the literature on assortative matching. From the theoretical perspective, Becker (1973) has defined positive assortative matching as a pairing in which there is positive correlation between the abilities of two spouses. Shimer \& Smith (2003) introduce frictions in the matching market and define additional conditions in which matching holds. Smith (2006) provides further extensions and Smith (2011) reviews the literature.

From the empirical side, Abramitzky et al. (2011) and Angrist (2002) consider the effect of sex ratios on assortative mating. Theoretically, as long as matches are constrained to consist of a male and a female, an unbalanced sex ratio endows one gender with an advantage in securing a better partner with respect to an environment with a balanced sex ratio. The crime market is characterized by unbalanced sex and race ratios, however, matches are not constrained in composition and this allows me to empirically pinpoint a discrimination bias.

Empirically, my approach differs by the employing of an ability measure, rather than a signal of ability as is e.g. education in Rose (2007) and Pencavel (1998). I take the difference in the ability of partners, rather than regressing the trait of one partner on the traits of the other, as does for e.g. Pencavel (1998) and I take the analysis a step further into the realm of discrimination.

Finally, this paper is related to the economic literature on crime. Starting with Becker (1968) research has addressed individual decision making and aggregate relationships, however, not in the context of co-offending. The latter matter is missing in the recent review of Levitt \& Miles (2007). The criminological literature has given more attention to the organization of small crimes and Alarid et al. (2009) provide evidence from prison interviews that offenders choose to commit a crime with a friend from the same social circle resolving issues of trust by matching along social ties. van Mastrigt \& Carrington (2013) provides a review on the literature from the perspective of network homophily 
(similarity in observables) in group offending, noting that there is an incentive to select a successful partner, however stopping short at selecting him from the local offender pool and not considering the implications of this incentive, as it is done in this paper.

This paper links the literature on assortative matching with that on crime and discrimination. The novel empirical design conveys the essential message that considering positive assortative matching as characterizing matches, and taking into account productivity differences between demographic groups, one can refer systematic differences in ability within a match to taste preferences on observable traits. The identification comes from the endogenous match formation, and by virtue of arrest revealing ability. The model shows that even in cases where a taste bias is exercised it might go undetected in the data, showing that the empirical result is a necessary but not a sufficient condition to pin point biases.

Conceptually assortative matching and discrimination are linked through the significance of observable traits in the matching choice. When choosing a partner based solely on ability, observables should not predict significantly the partner choice. When matching is based on an observable trait, discrimination, there assortative matching on ability fails. Essentially, my empirical strategy determines whether matching is based on observables in the presence of incentives to match on ability and I find that criminals like to indulge their costly discriminatory biases.

The structure of the paper is the following. First, in section 2, I present the data. Section 3 describes a simple static matching model that will aid the intuition with the identification strategy and interpretation. Sections 4 and 5 discuss the empirical strategy, results and robustness checks. Section 6 concludes.

\section{Data}

The source of criminal data for this paper is the National Incident Based Reporting System (NIBRS), covering criminal incidents in the United States. The sample period runs from 1995 to 2010. NIBRS consists of repeated cross-sections, where the data points are individual level records on crime incidents submitted by law enforcement agencies. These records provides details on how many perpetrators were involved in one incident, their characteristics and the characteristics of the crime. The NIBRS data is not representative for the US. In 1995 agencies in 9 states submitted data, while 2010 there were 36 states. Given the amount of collection and submission effort (presumably, it is costlier for bigger agencies), the NIBRS is skewed towards crimes in the jurisdictions of smaller and medium-sized agencies. In a given county there can be from 1 to several agencies, depending on population size and historical factors. Given that one city can be overseen by several law-enforcement agencies, which have a traditional focus on neighborhoods or types of crime, it is likely that outcomes within an agency's jurisdiction are correlated, so I cluster the errors on this variable and provide a robustness check with city specification.

Property crimes are a unique segment of crime where offending is relatively independent of diverse physical endowments between genders. For this reason, I select all the property crimes according to the Uniform Crime Reports 
code for the following crimes: arson, robbery, burglary, larceny offenses such as pocket-picking, purse-snatching, shoplifting, theft from building, theft from coin operated devices, theft from car or car, all other larceny and selling of stolen property.

For a given year, I exclude agencies that do not report at least one crime for a week, similar to Dahl \& DellaVigna (2009) and concentrate my analysis on crime commited in a couple. Dropping individuals for which all the characteristics of gender and race are known, leaves me with 98 percent of the data. I select individuals between 15 and 65 years of age, leaving out offenders who are unreasonably young or old and, thus, 87 percent of the observations remain. Selecting the full couples amounts to 78 percent. In the robustness checks I concentrate my analysis more on the arrests where the observables are known with a higher degree of certainty and on daylight crimes to control for the reporting bias. I concentrate my analysis on black and white criminals, but I provide robustness checks with the other races in the sample. Law-enforcement agencies do not seem to follow a specific pattern in recording the order of criminals in an incident and records are as if randomly assigned. Nevertheless, I randomize their order by generating a uniform distribution and assigning first for the criminal whose value is less than the mean.

Table 1 presents the summary statistics for criminal partners. The average criminal is 25 years old white male, he commits 1 offense per crime incident. It is worth keeping in mind that one crime incident might involve several offenses, for e.g. assault and robbery are counted separately as offenses. He faces a 0.6 probability of success, defined as the probability of not being arrested. The average difference in age between offenders in a group is 0 years, but the mean of the absolute (as in $\mid$ AgeGap $\mid$ ) value is 4 . The variable agency denotes the average diversity within the jurisdiction of an agency. This variable is equal to the frequency of females times the frequency of whites. It would attain value of 0 or 1 if a given market is homogeneous in the type of criminals. With a relatively high standard error it shows that there is heterogeneity between criminal markets. In total there are 1,857,272 individual observations, yielding 928,636 observed partnerships over the sample period. In the following empirical analysis a couple corresponds to one observation and not to two, as is the case with dyadic data analysis.

Table 2 presents the cross-tabulation of pairs. The first column shows the total frequency of the 4 types: black males, black females, white males and white females. The second column denotes the success rates for each type. The remaining columns in table 2 show how often does a category of criminal, for e.g. white male, choose a criminal in the other category. Note that black males emerge as the most successful and white females as the least successful criminals. In $78 \%$ they pair up with other black males, followed by black females. Black females choose one another in $67 \%$ of the cases. White males choose other whites in $94 \%$ of the cases, of which 74 percentage points are other white males. White females have a similar preference for other whites, but $51 \%$ of them also choose their own gender. Cross-race matches occur on average in $10 \%$ of the cases for each type of criminal. On average, each type prefers his own type as a partner.

In order to establish a pattern of matching it is necessary first to refute that partners are randomly drawn from the distribution of criminals. In table 2 it is observed that on average criminals prefer partners of their own type. A further 
Table 1: Summary Statistics

\begin{tabular}{lcc}
\hline & Mean & SD \\
\hline White & 0.650 & 0.477 \\
Female & 0.307 & 0.461 \\
Age & 25.618 & 9.875 \\
Success & 0.603 & 0.489 \\
Offenses & 1.014 & 0.132 \\
Age Gap & 4.426 & 6.369 \\
Agency & .071 & .256 \\
\hline Observations & 1857272 &
\end{tabular}

Notes: An observation is a criminal in a crime committed in jurisdiction of an agency in certain date and hour. Variables white and female are dummies. Age takes values between 15 and 65 . The success rate is the complement to the arrest rate. Each criminal has one or more offenses on his record for the crime reported. Age Gap refers to the absolute difference in ages between two partners. Agency takes a value 1 whenever in a given year-agency cell the market is restricted to only whites, only blacks, only females or only males.

Table 2: Cross Tabulation of Pairs

\begin{tabular}{lcccccc}
\hline & Total & Success & Black Males & Black Females & White Males & White Females \\
\hline Black Males & 0.261 & 0.717 & 0.779 & 0.283 & 0.051 & 0.048 \\
Black Females & 0.089 & 0.518 & 0.097 & 0.630 & 0.005 & 0.025 \\
White Males & 0.433 & 0.600 & 0.084 & 0.025 & 0.737 & 0.413 \\
White Females & 0.217 & 0.507 & 0.040 & 0.062 & 0.207 & 0.514
\end{tabular}

Notes: An observation is a type of criminal in crime committed in jurisdiction of an agency. The types here are 4 : black males, black females, white males, white females. The columns sum to 1 . 
Figure 1: Bias against Matching with Males

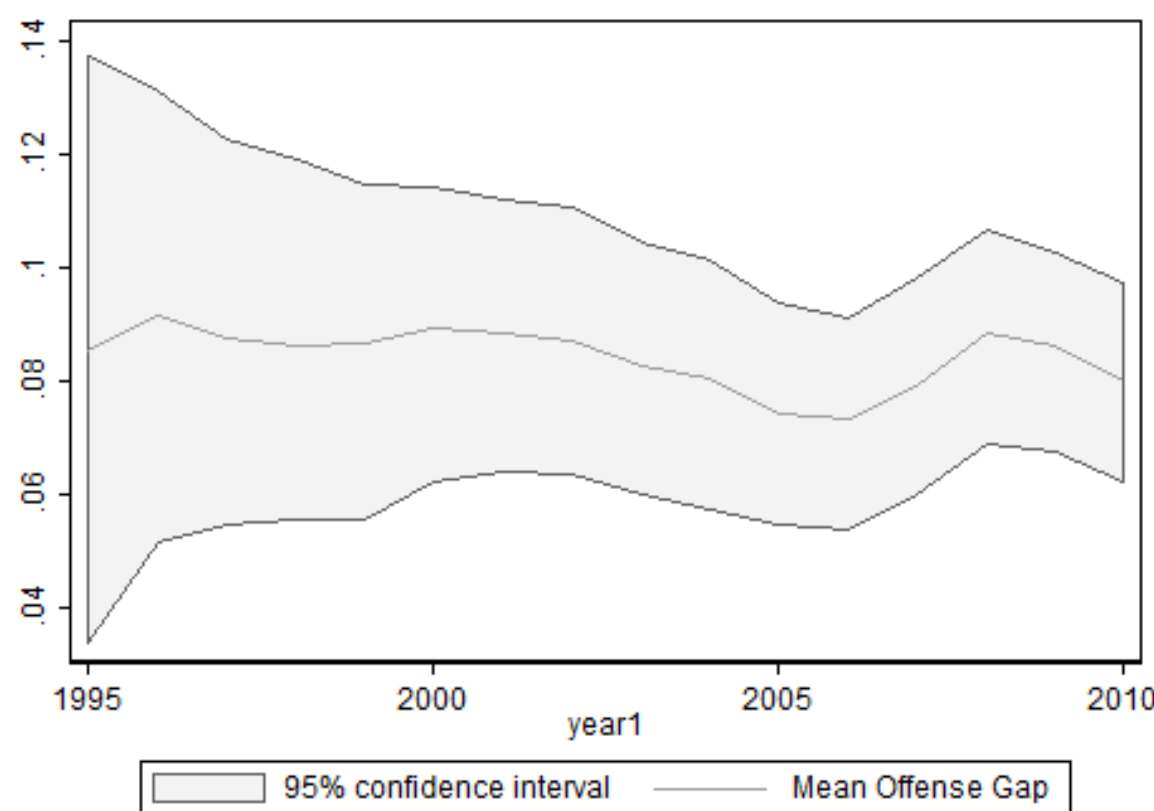

Note: This figure plots the gap between $\operatorname{Pr}($ female, female $)$ and $\operatorname{Pr}($ female $) \times \operatorname{Pr}($ female $)$. Whenever the gap differs from 0 this is an evidence of a bias in matching. The confidence intervals are constructed through 1000 bootstrap draws of 10000 observations each. The larger confidence intervals at the beginning of the sample may reflect the ongoing collection effort of NIBRS, as the observations in 1995 are less than in 2010.

evidence of bias can be easily seen with the following reasoning. Consider the probability of observing a pair of two females:

$$
\operatorname{Pr}\left(\text { female }_{1}, \text { female }_{2}\right)=\operatorname{Pr}\left(\text { female }_{1}\right) \operatorname{Pr}\left(\text { female }_{2} \mid \text { female }_{1}\right)
$$

If 2 partners match up randomly, then $\operatorname{Pr}\left(\right.$ female $_{2} \mid$ female $\left._{1}\right)=\operatorname{Pr}\left(\right.$ female $\left._{2}\right)$. The probability of ending up with a female partner would be independent from the own gender. In figures 1 and 2 I plot the difference between the sample frequencies of $\operatorname{Pr}\left(\right.$ female $_{1}$, female $\left._{2}\right)$ and $\operatorname{Pr}\left(\right.$ female $\left._{1}\right) \operatorname{Pr}\left(\right.$ female $\left._{2}\right)$ with respect to gender and race. The figures have been obtained with bootstrapping - by repeated drawing of subsamples and calculating the difference between the abovementioned frequencies. The line indicates the mean and the confidence interval is taken over the distribution for each year. In figure $1 \operatorname{Pr}\left(\right.$ female $_{1}$, female $\left._{2}\right)>$ $\operatorname{Pr}\left(\right.$ female $\left._{1}\right) \operatorname{Pr}\left(\right.$ female $\left._{2}\right)$, indicating that $\operatorname{Pr}\left(\right.$ female $_{2} \mid$ female $\left._{1}\right) \neq \operatorname{Pr}\left(\right.$ female $\left._{2}\right)$ and thus the choice for another female with whom to form a match is not independent of own type. The same pattern can be observed in figure 2, showing that matching is not random also in the dimension of race.

In both figures, correlational evidence shows that criminals do not form partnerships randomly and that they segregate on observable characteristics. It is not possible to distinguish whether these patterns are caused by positive assortative matching on ability between people who happen to be of the same gender or by a specific gender bias in matching. The model in the next section 
Figure 2: Bias against Matching with Blacks

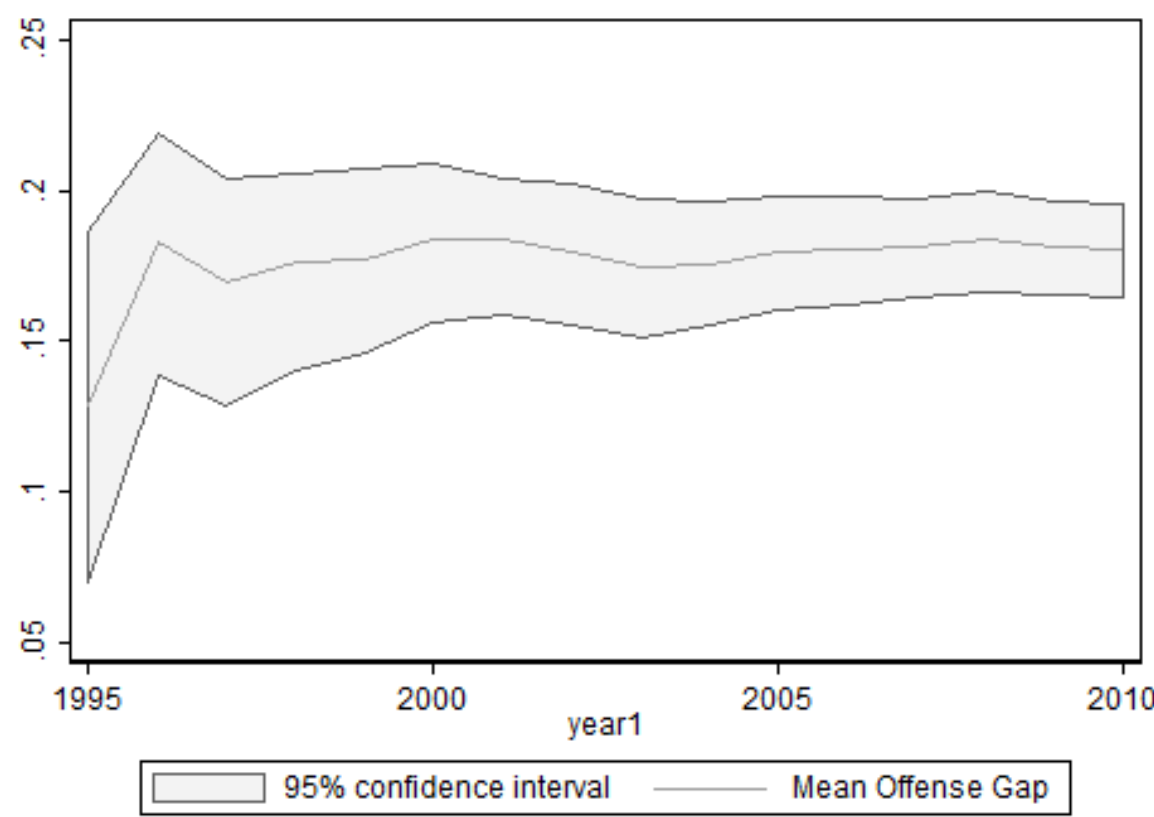

Note: This figure plots the gap between $\operatorname{Pr}($ white, white $)$ and $\operatorname{Pr}($ white $) \times \operatorname{Pr}$ (white). Whenever the gap differs from 0 this is an evidence of a bias in matching. The confidence intervals are constructed through 1000 bootstrap draws of 10000 observations each. The larger confidence intervals at the beginning of the sample may reflect the ongoing collection effort of NIBRS, as the observations in 1995 are less than in 2010. 
shows how the following empirical evidence can be interpreted.

\section{Model}

In this section I will introduce a simple model of assortative matching, which will introduce the grounds for the empirical strategy in the next section.

When a suitable crime opportunity presents itself, a criminal has to choose a partner with whom jointly to exploit it. A partner might be required for a variety of motives - for e.g. complementarity in skills, mentorship or courage. While motives differ in the individual case, policing technology provides an incentive. Given the practice of offering a plea bargain to the criminal partner arrested first, each criminal associate faces the incentive to pair up with the most successful possible counterpart, or, put simply, one who would not get arrested and who would not "sing" to the police, if arrested. Therefore, any criminal would consider a partner through her ability level. Considering the incentive for a successful associate from both sides of the partnership, it seems straightforward that there should be positive correlation between criminal ability traits between partners.

Consider a given partnership as a match, where there can be 3 patterns in the correlation of ability between partners. First, a pattern of random matching, when there is no correlation of criminal's traits within the partnerships. Second, negative assortative matching is a pattern in which the most able partner prefers the least able one, leading to an empirical observation of negative correlation of ability between partners. Third, positive assortative matching is a pattern, where empirically there is positive correlation of ability. One can think of these patterns as corresponding to certain incentives and motives, as in the first benchmark case there would be no motive at all. In the second, there can be a learning motive, where the higher able partner wants to teach, so he would want to select the least able partner possible. The final pattern would be consistent with the arrest incentive, where a partner would prefer a counterpart that is at least as able as him as not to get arrested.

Introducing the criminals, assume that there is a unit continuum of them, each indexed by an exogeneous probability of success $p \in[0,1]$. p is strictly increasing in ability, that is, criminals with a high $p$ are more able than criminals with a low $p$. Assume that there are $\mathrm{M}$ demographic groups of criminals and criminal ability is distributed similarly among them. Given that a match is composed of 2 criminals, I will consider equilibrium outcomes between group $\mathrm{m}$ and $\mathrm{n}$. Criminals get an exogeneous individual random return on criminal activity $Y \geq 0$. Consider a perfect information case and assume that a criminal observes the real ability of his partners, so that he chooses between associates that are better or worse than him in this one measurable attribute. Also, assume that the criminal has a preference to work with partners from a certain demographic group. With discrimination choosing potential partners is non random with respect to observables, as the matching choice is due to them.

Without loss of generality, assume that criminals are ordered as 1 and 2 in a partnership. The behavioral assumptions are that both partners have to agree to the match and that once a crime is commited they part ways.

Let the additional utility $T_{m}$ denote a taste from committing a crime with a partner from the other demographic group, such that the preference for the 
own group is 0 . The behavioral assumption behind it is that it is exercised in the contingencies in which the criminal succeeds. A criminal maximizes his expected utility with respect to his partner's success probability:

$$
\begin{aligned}
E U_{m n}\left(p^{2}\right)= & p_{m}^{1} p_{n}^{2}\left(Y+T_{m}\right)+p_{m}^{1}\left(1-p_{n}^{2}\right)\left(Y-S+T_{m}\right)+ \\
& p_{n}^{2}\left(1-p_{m}^{1}\right) 0+\left(1-p_{n}^{2}\right)\left(1-p_{m}^{1}\right) 0
\end{aligned}
$$

where $p_{m}^{1}$ and $p_{n}^{2}$ are the probabilities for success respectively for criminal 1 from group $m$ and his partner 2 from group $n$. If criminal 1 gets arrested he gets a disutility, which is normalized to 0 . If he does not get arrested he will get the return $Y$. In the special case when his partner gets arrested he will get the same return because they would have already parted and shared the booty, but instead of a higher probability of arrest he will loose the additional utility $S>0$ for the security that his partner implicitly provides by staying away from the law-enforcement ${ }^{123}$.

The expected utility is increasing in the probability of success of the partner, ensuring a preference for the most able partner. The higher the ability of the choosing criminal, the higher is the marginal utility from the partnership with a better partner ${ }^{4}$. Given the same preference for the partner, mutual acceptance of matches ensures that each criminal will pair up with one of similar ability in equilibrium.

Consider first the "tasteless" case, where $T_{m}=0$ and $p^{1}=p_{2}$ is an equilibrium, referred to later as unbiased matching. Assume that all criminals have a reservation ability of $p^{1}$, equal to their own ability. If 1 criminal deviates and lowers his reservation ability, that is, he accepts a partner that has a lower ability than him $p_{2}<p^{1}$, then he would be worse off. If he would consider a partner with $p_{2}>p^{1}$, then nobody else would match with him, because everybody else has the strategy to match with a partner of their own ability and he would get 0 .

If all criminals have a lower reservation ability (than their own), then one can deviate profitably by matching up with a higher ability criminal. If all criminals have a higher reservation ability, then nobody would agree to a match (except among $p_{i}=1$ ) because the possible counterpart with $p_{2}>p^{1}$ would want to match with someone of even higher ability $p^{3}>p^{2}>p^{1}$. Therefore, matching with a partner of the same ability, $p^{1}=p^{2}$, is a Nash equilibrium.

\footnotetext{
${ }^{1}$ The additional utility $\mathrm{S}$ provides an incentive for the partner not to remain single. If the interaction between $\mathrm{S}$ and $\mathrm{Y}$ was multiplicative, instead of additive, then $S<1$ would imply that the utility of both partners succeeding is higher than the utility in the case of the other partner being arrested, which is consistent with the plea-bargain incentive. Setting $S=Y(1-\alpha)$ would relax the behavioral conditional independence assumption, where $\alpha$ is the additional probability of success in case the partner gets arrested, whose realization occurs after the matching choice has been completed.

${ }^{2}$ The individual disutility of jail can be normalized to 0 without loss of generality. The parameters $\mathrm{S}$ and $\mathrm{Y}$ are assumed to not vary systematically with respect to different probable partners of the criminal who chooses and there is no explicit sharing rule. In a sense, they are crime specific. For e.g. if a criminal decides to rob a bank he knows that he would earn a certain amount no matter the partner and because of the crime he would face a disutility if his partner get caught. One of the empirical robustness checks controls for the monetary return on crime and the matching results do not change. Furthermore, differing Y falls into the domain of search frictions, see for e.g. Smith (2011).

${ }^{3}$ If $T_{m}$ 's influence on the utility was somehow multiplicative then the basic intuition would remain the same - a positive taste allows for a partner of a relatively lower ability than own, the converse for the negative taste.$$
\frac{\partial E U}{\partial p_{2}}=p^{1} S
$$ 
Figure 3: Distributions of groups of criminals

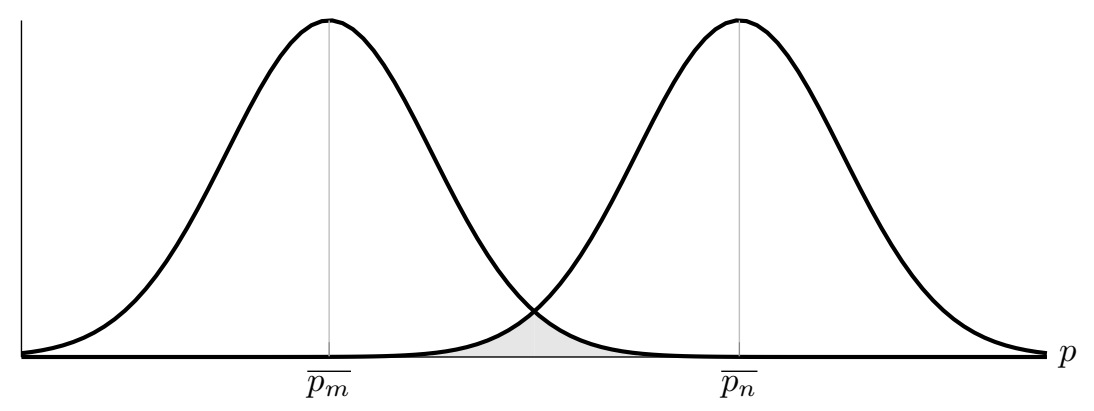

The matching pattern can be described through figure 3 . Let the individual ability $p_{m i}$ to be distributed with a pdf $F$ with mean $\overline{p_{m}}$ and finite variance $\delta_{m}$. Within each $\mathrm{m}$ group there is a heterogeneity of ability. Consider the matches between 2 groups, $\mathrm{m}$ and $\mathrm{n}$, and assume that $\overline{p_{m}}<\overline{p_{n}}$. In equilibrium, at the individual level the difference in ability between partners would be 0 . If the distributions of ability of criminals of groups $m$ and $n$ are coinciding along an interval, as in figure 3 , then there would be matches between the 2 groups. If criminal $\mathrm{j}$ from group $\mathrm{n}$ draws a low ability and criminal i from group $m$ draws a high ability, then they could form a match. For e.g. this would practically imply that while the white males have a lower productivity mean than the black males, the white in a black-white group can presumable have a higher criminal ability than the average white in a white-white group. Otherwise, the 2 groups would segregate by creating matches within their own groups, as in the left tail of the distribution of the criminals from group $m$.

Relaxing the "tasteless" assumption, consider the second case of matches between groups $m$ and $n$ from the perspective of the $m$ criminal:

$$
E U_{m n}=p_{m}^{1}\left(Y-S+p_{n}^{2} S+T_{m}\right)
$$

When the criminal considers a partner from his own group he does not exercise a taste, so that matching within a group, if preferred, is unbiased and $p_{m}^{1}=p_{m}^{2}$

$$
E U_{m m}=p_{m}^{1}\left(Y-S+p_{m}^{2} S\right)
$$

Taking the difference in utility when a member of group $m$ chooses between committing a crime with a member of group $m$ and a member of group $n$ :

$$
E U_{m m}-E U_{m n}=p_{m}^{1}\left(S\left(p_{m}^{2}-p_{n}^{2}\right)-T_{m}\right)
$$

Any asymmetry between group preferences would create a pattern in which there is biased matching, such that $p_{m} \neq p_{n}$. If at least one of two groups strictly prefers matching within itself, then the other group cannot match with it, regardless of its preferences. This would lead to segregation and unbiased matching within group and a taste parameter cannot be empirically identified because there are no between group matches observed. 
Therefore, for between group matches it is necessary that $E U_{m m}-E U_{m n} \leq 0$ and $E U_{n n}-E U_{n m} \leq 0$, such that matching between groups is preferred or indifferent to both groups. $E U_{m m}-E U_{m n} \leq 0$ would be equivalent to:

$$
p_{m}^{2}-p_{n}^{2} \leq \frac{T_{m}}{S}
$$

where, given that $p_{m}^{1}=p_{m}^{2}$, some algebra and dropping the criminal subscripts:

$$
p^{m}-p^{n} \leq \frac{T_{m}}{S}
$$

An equilibrium requires a 2 sided taste compatibility. Replacing $p^{m}$ for the equivalent expression in equation 2 and more algebra, earns the equilibrium condition for mixing between groups:

$$
T_{m}+T_{n} \geq 0
$$

In figures 4 and 5 the matching choices are depicted. Figure $4 \mathrm{a}$ shows the intuition behind the choices, following taste preferences of the $\mathrm{m}$ group criminal. The between group matching condition states that criminal $\mathrm{m}$ would prefer any $\mathrm{n}$ criminal above the line defined by $T_{m}$. For $T_{m}>0$ this includes the 45 degree line, along which unbiased matching occurs. As it is illustrated, if $T_{m}>0$ then $p_{n}<p_{m}$, for a positive taste the criminal would be fine with a partner with a lower ability level than his. For a negative taste, $T_{m}<0$, he would match with a partner from this demographic group only if he is of higher ability $p_{n}>p_{m}$.

The shaded area in figure $4 \mathrm{~b}$ depicts the matching choices, where the 2 taste terms are positive $T_{m}=T_{n}>0$ and matching sets are compatible ${ }^{5}$. In this area, each line parallel to the 45 degree line illustrates a Nash Equilibrium. For e.g. if all criminals have the strategy to match with someone of equal ability, anyone deviating would be worse off or not finding a match, like in the unbiased matching case.

Similarly, in figure 5a I consider the asymmetric case, where the $\mathrm{n}$ group has no taste preferences, while the $\mathrm{m}$ group has a positive taste to commit a crime with them. The Nash Equilibria occur within the shaded area. Finally, in figure $5 \mathrm{~b}$ the tastes of the two groups are opposite, $-T_{n}=T_{m}>0$, and the unique equilibrium is at $p_{n}<p_{m}$. In between these 2 figures is the case where one group has a negative taste, which is not as big as the positive taste of the other group, $T_{m}>-T_{n}>0$, earning an equilibrium allocation in the middle between the 2 lines and, again, $p_{n}<p_{m}$. In this case, the empirical observation of biases would be a a necessary and sufficient condition for their existence.

Given that $T_{m}$ is demographic group specific, it could be identified from the observables in the data. If one runs the regression counterpart of equation 2 $p_{m}-p_{n}$ on $\beta T$, where $\mathrm{T}$ denotes the difference in observable trait for the $\mathrm{n}$ partner with respect to $\mathrm{m}$, then its coefficient $\beta$ would be the taste difference from matching. If $\beta$ is positive, for a criminal from group $m$ (the first in the pair) matching with a different group $\mathrm{n}$ is preferable to matching with his own group, and empirically $p_{m}>p_{n}$. Following the theoretical model, $\beta$ could be 0 , and yet there could be taste preferences in choosing a partner. Finding a matching 2 .

${ }^{5}$ Compatibility as defined by the intersection of the 2 half-planes, defined by the condition 


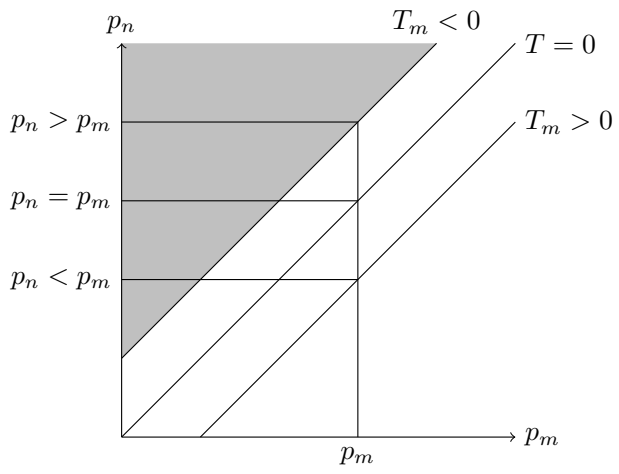

(a) Tastes of Group m

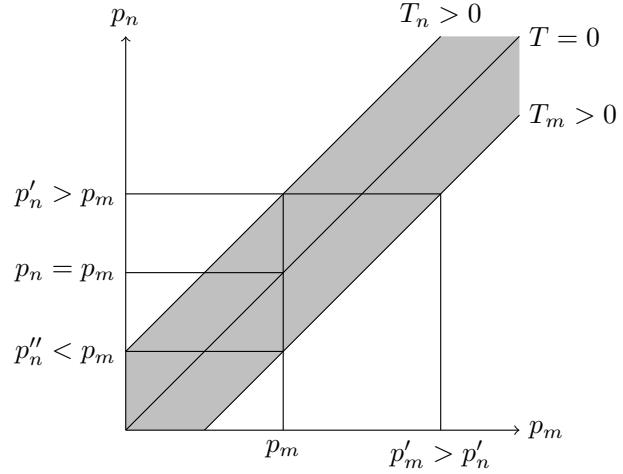

(b) Positive Tastes

Figure 4: Matching with Tastes

Note: Figure 4a plots the desirable matches from the perspective of the criminal from the $\mathrm{m}$ group. Both in the case of $T_{m}<0$ and $T_{m}>0$ he desires partners from the half-plane above the lines defined by the taste terms. Figure $4 \mathrm{~b}$ plots the 2 side desirable matches from the perspective of both criminals.

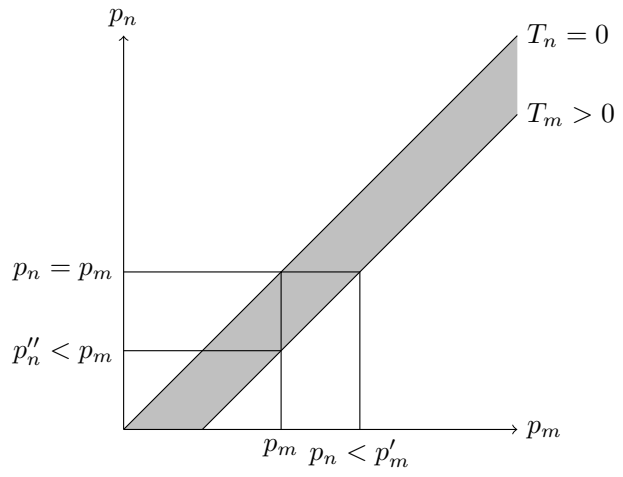

(a) One Taste

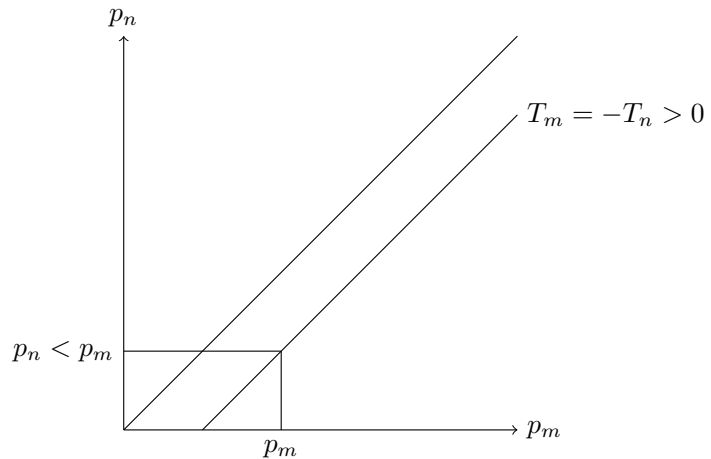

(b) Opposite Tastes

Figure 5: Equilibrium Matching

Note: Figure 5a plots the matching set for 2 criminals groups, for which $T_{n}=0$ and $T_{m}>0$. The equilibrium matching set is the shaded area between the 2 taste lines. Figure $5 \mathrm{~b}$ plots the matching set for $T_{n}<0$ and $T_{m}>0$, such that $T_{n}=-T_{m}$. In this case the equilibrium matching set is a line, along which $p_{m}>p_{n}$ 
allocation outside of the 45 degree line with bet $a \neq 0$ is a sufficient condition to say that there are taste preferences, but it is not a necessary statistic.

Ideally, one would want to have several observations over the same criminal pair in order to pinpoint the fine difference between $p_{m}$ and $p_{n}$ in a match. The lack of such detail in the data is compensated by many observations, that can relate the systematic differences in the underlying quality of the match to observable traits. Therefore, positive assortative matching characterizes matches in the criminal market, and systematic differences in ability correlated to matches between different groups can be referred to taste preferences on observable traits.

\section{Empirical strategy}

The prediction that $p^{1}=p^{2}$ means that criminals in a pair are of similar quality. This would be apparent in couples where both criminals were arrested or not and the observed difference $p^{1}-p^{2}=0$. In pairs in which only one criminal got arrested both of them would be convinced that their quality is similar, but the realization of arrest could indicate that their probability is different. From the point of view of the offender both partners face the same probability of getting caught and arrest is a random realization of policing, not a systematic mistake due to bias. On the aggregate, I can infer whether these mistakes amount to a systematic bias correlated to gender.

If the probability of success can be summarized by the empirical equation:

$$
p^{1}=a_{1}+a_{1} \times a_{2}
$$

where the probability of success is an increasing function of the ability of the criminal $a_{1}$ and a separable crime-specific interaction between his ability and the one of his partner $a_{1} \times a_{2}$, so that, the probability of success is a function of own and couple incident specific characteristics ${ }^{6}$. Taking the difference between the 2 success probabilities would cancel out the crime specific term, so that:

$$
p^{1}-p^{2}=a_{1}-a_{2}
$$

In order to test this I estimate the equation:

$$
p^{1}-p^{2}=\left(X_{1}-X_{2}\right) \beta+v
$$

The net difference in characteristics $X_{1}-X_{2}$ contains the variables white, female and age. For e.g. white $=$ white $_{1}-$ white $_{2}$, where white $_{1}$ and white $_{2}$ are dummies for white race for criminal 1 and 2 respectively. For a blackwhite pair white $=0-1=-1$. Given that the order of the criminals within the pair is randomized, a symmetry of coefficient size is imposed, such that $\beta_{\text {white }_{1}}=-\beta_{\text {white }_{2}}{ }^{7}$.

More formally, under the null $H_{0}: \beta=0$ the difference between the 2 abilities should be 0 on average and not correlated to observables. This would be equivalent to unbiased matching. Under the alternative $H_{1}: \beta \neq 0$, the

\footnotetext{
${ }^{6}$ A general form for this representation is $p^{1}=A\left(a_{1}\right)+B\left(a_{1}, a_{2}\right)$, where $\mathrm{A}$ is an increasing function of ability and $\mathrm{B}$ is symmetric in its arguments.

${ }^{7}$ The symmetry is present also when estimating as a robustness check a specification with separate $\beta$ 's for the two offenders.
} 
matching choice is driven by an observable characteristic, therefore, there is a net difference in taste.

In all the following examples the order of the criminals defines the interpretation of the independent variables, therefore read "male-female" as first criminal is male and second criminal is female. Following the theoretical model, the taste interpretation is from the point of view of the first, male, criminal and the variable that denotes the "switch" of demographic group is the coefficient on $X_{2}$, or the negative of the coefficient on a given trait.

The couple incident specific effect is canceled out by taking the difference in probabilities. This includes distance from law-enforcement agents, number of policemen on patrol on the day of the crime, crime characteristics and other traits of the partnership, as well as location specific fixed effects ${ }^{8}$. Search frictions are presumably not a concern. Shimer \& Smith (2003) and Smith (2006) show that in the presence of frictions the difference in ability should be close to 0 , as the null hypothesis predicts.

The dependent variable $p^{1}-p^{2}$ can take the values $\{-1,0,1\}$ and has a mean of zero. Consider the case of a couple with white males. Taking observables as regressors, would define the perfect match as every match in which both partners share the same observable characteristics. On one side, the criminals in this pair will have equal empirical individual $p$ 's (as predicted by observables). On the other, if they exhibit a difference in ability it will not be correlated to observables, because there is no variation in them.

Identification would come from pairs with for e.g. a black male and a white male that would have $p^{1}>p^{2}$, and a positive dependent variable. The difference in ability would be correlated to observables, identifying the coefficient on the variable white. This coefficient would capture the taste matching bias for blacks. Anticipating the results, a negative coefficient on white would mean that as the second partner is white the independent variables itself becomes negative, earning a positive difference between the probabilities of success of the black and white males. This would mean that black males have a positive taste for matching with whites, and equivalently, whites have a distaste for matching with blacks. If white $=0$, matching is unbiased along this dimension or a bias cannot be identified.

The first column in table 3 presents the baseline results from the estimation of equation 6 are presented. The following columns show diverse robustness checks which will be discussed in the next section. The coefficient on white is negative, while the coefficient on female is positive. In table 4 the regression results are presented within the context of the group success means. The first 2 columns denote the unconditional values of $p^{1}$ and $p^{2}$ in the sample. The last 2 columns show the estimated differences, following equation 6 .

In male-female groups females have a higher probability of success. The coefficient on female is positive, and the independent variable is negative, showing that on average females are less likely to get arrested when they are in a male-female group. The net bias difference is negative ${ }^{9}$, showing that from the perspective of the males the taste for forming a group with females is lower than the taste for other males. Given that this is an equilibrium outcome, females

\footnotetext{
${ }^{8}$ Location specific fixed effects are included in some of the robustness checks.

${ }^{9}$ female $^{8}$ female $_{1}-$ female $_{2}$, where female $_{1}$ and female fe $_{2}$ are dummies for both partners for female genders. In this example female $=0-1=-1$. The variable that denotes the difference in demographic characteristics is female $_{2}$, which enter the equation with a negative sign.
} 
have a positive taste for matching with males, so that their probability of success can be lower than the female's.

Consider the pair of a black male and a black female. For them the dependent variable should be positive, because on average black males face a higher probability of success than black females, as seen in table 4 . Therefore, $p_{\text {blackmale }}-p_{\text {blackfemale }}>0$ in such a match. However, the coefficient on female is positive meaning that $p_{\text {blackmale }} \widehat{-p_{\text {blackfemale }}}<0$. Therefore, on average black females have lower probability of success than black males, but whenever they form a cross-gender partnership they are of higher ability. A similar pattern can be observed in the white male and female pair, where while white males have a higher likelihood of success, in the observed matches they are of a lower criminal quality. In other terms, females either have a higher probability of success than the average of their gender or they accept a male from below the average and they compensate for the negative bias with a higher success rate.

As already interpreted, in a black-white couple whites are more likely to get arrested. The estimated coefficient on race is negative, hinting at positive net bias, such that for blacks the taste for their own group is smaller than the taste for the whites. Thus, whites do not need to be of similar ability in order to form a match with blacks.

Finally, the only partnership type of differing race and gender, where both partners face the same relative probability of success is the one between black males and white females. On average white females have a much lower average mean of success, but when they are in a couple with a black they don't have a compensating higher probability of success. The net bias is equal to 0 , hinting at either no biases on observables for these matches or the preference for whites is compensated by the distaste for females, such that partners from these 2 groups match on ability.

The underlying assumptions of the above interpretation are several. The identification strategy can be stated as follows: under positive assortative matching the differences in the ability measure should be small. If they are explained by observables, then this is a hint of systematic bias in matching. The assumption of the interpretation of arrest as a predictor of criminal ability is based on anecdotal evidence according to which criminals of higher ability are the ones that do not get caught. Unfortunately, this cannot be tested with present data to the best of my knowledge.

Second assumption is that both partners face an equal probability of arrest, conditional on the incident. In other terms, police exerts equal effort to catch each partner. If this were not the case, then the above results would be interpreted also with respect to police effort. However, this would mean that the police are more eager to arrest the male in a male-female pair and the white in a black and white pair. I know of no evidence for this case.

Third, regression results might pick up unobservable characteristics that are systematically correlated to the difference in observable ones and define the preferences for criminal partners. The case of bias related to observable characteristics rests, but the broader implications of differing criminal ability between groups could rationalize the case for selective general policing. 


\section{Robustness checks}

In this section I present some robustness checks. First, in column 2 of table 3 I present estimates with interacted fixed effects for year and reporting agency. Results remain the same, consistent with notion that location crime specific effects are canceled out in the differencing of the successes between the 2 partners. Second, measurement error for non-arrested couples could impact the estimates, because of reporting bias. In order to assess this issue, I exclude them from the sample and estimate again equation 6 . The results are presented in column 3 of table 3. Coefficients do not change in sign, but they increase in absolute terms. This could be due to two reasons: either the measurement error attenuates estimates, or, in this way I exclude the group of criminals that were less likely to select one another on observable characteristics.

In column 4 of table 3 I show that monetary return does not matter for the choice of a partner, by including it as a covariate. In other words, the size of the stolen loot does not seem to predict differential matching. In column 5 the sample is limited to partnerships whose members are older than 29 years. These offenders are more experiences and the quality of the pairing should be better. Yet, there is a persistent negative effect for whites. In column 6 the sample is limited to those crimes that were reported to have occurred in daylight hours, between 8 and 19. This check minimizes the reporting bias due to the cloak of the night. In these crimes at least one of the offenders was arrested (thus, subsample of the sample in column 3) and results are similar in magnitude to the ones in column 3 , but different in size.

One of the channels of relaxing search frictions in the crime market is to search for partners within the own gang. In column 1 of table 5 I control for gang affiliation, which would ease the formation of partnerships and it does not change results. The variable for gang is significant at the $5 \%$ level. The negative coefficient shows that in matches of non-gang and gang members, the gang ones are more likely to get arrested. This could be either due to inherent differences between individual criminals and criminals from gangs, where the former are less likely to get arrested, or, law-enforcement has an easier access to gangsters due to for e.g. informants. In column 2 I include the full choice set of races and results remain the same and none of them significantly different from the black reference category. In column 3 I control for same offense if criminals commit the same offense they would be better able to judge one another. However, results remain the same. In order to partially disentangle learning from all reasons for matching, I restrict the sample by the age differences between 2 offenders. In column 4 of table 5 the sample is restricted to only those pairs whose age difference within is less than 5 years ${ }^{10}$. For the first time the age variable shows a significant direction, hinting that older offenders are less successful, while the coefficient on race is lower. This is consistent with a bias for older partners, where they turn out to have a lower ability than the younger one and they enjoy a bias premium in their favour. This age effect could be also due to strategic policing, especially when both offenders are young and the older one is considered to be the "bad influence", or, because the older offender is more likely to have a file with the police. In column 5 I exclude observations from a given agency-year in which the observed partnerships were only between blacks

${ }^{10}$ The choice of age gap is arbitrary, but representative of the results that the reader can find in the appendix for different gaps. 
or between males. Such a criminal market would suffer from non availability of other partners and the results remain the same, given that identification comes from the pairs with differing observables. In column 6 I aggregate the agencies into cities and control for city-year fixed effects. The results remain robust throughout all specifications.

Disaggregating the results by crime types in table 6 shows that the effect for whites is observed in shop-lifting, theft from building and robberies. The effect for females is driven by thefts from and of motor vehicles, burglaries, robberies and other larceny and stolen property offenses. Surprisingly, there is barely an effect for females in shoplifting, a crime traditionally associated with their gender. This could be either due to the fact that most matches in this crime sector are between females, or there is just no negative bias for females, consistent with their associated reputation. In shoplifting and robberies age is an asset, while in car theft it is a liability.

Further on, in the appendix one can find robustness checks extending columns 4 and 5 from table 5 and results from multinomial logit estimation of equation 6 , as well as, separating the coefficients for the 2 criminals.

\section{Conclusion}

This paper analyzes partnerships among criminals and provides evidence for discriminatory bias in matching. I develop a model that predicts patterns of positive assortative matching on criminal ability. Arrest realizations allow me to pinpoint matches in which ability differs. Whenever only one of two partners got arrested this might hint on there being a difference with the criminal skills of the partners. If this difference is correlated to observable characteristics this might be evidence for a discriminatory bias. For example if in a group of two white males one gets arrested the difference between them would not be correlated to observable characteristics. However, if in a group between a black and white male the white one is more likely to get arrested, then the ability difference is related to the skin colour.

Therefore, I identify biases based on observable characteristics from the endogenous decision with whom to match. Discrimination is observed whenever one partner differs from another in an observable characteristic and faces a different probability success. In the case of gender, whenever females form a partnership with males they face a lower probability of arrest than males. Taking this together with the observation that on average females face a higher probability of arrest than males, means that in male-female matches females are either of a higher criminal ability than their average or males are of a lower criminal ability than their average. This is consistent with females undervaluing their ability (or males overvaluing theirs). Thus, males get a match premium that compensates for a taste disutility they incur, or, females have a taste for matching with males.

I make a similar observation on blacks, who despite having a higher success average, even when they form a partnership with whites they still face a higher success probability. Given assortative matching, this is consistent with black undervaluing their ability and having a positive taste for working with whites. For whites the reverse is true, they might exercise a negative taste for blacks. The grounds for this specific criminal preference could be rooted in the percep- 
tion that blacks are more likely to get stopped for general checks by the police, although in the data I find evidence that blacks are less likely to get arrested than whites.

Additionally, I find that these biases persist with age, but the discriminatory one on gender diminishes hinting at the hypothesis of statistical discrimination between males and females. I find an additional discriminatory bias between peers of similar ages, where if a 20 year old criminal forms a partnership with a 17 years old one, then he faces a higher likelihood of arrest. This hints at a pattern where the younger one compensates for his age with a higher ability. Other robustness checks include limiting the analysis to criminal market with demographically diverse offender pool and controlling for measurement errors by considering only couples where at least one person was arrested or the crime was commited in broad daylight.

This paper links assortative matching with discrimination in a novel empirical design. It makes a first step in describing matching patterns in the illegal criminal market, linking the crime literature with the literature on assortative matching and discrimination. As an implication this paper offers a perspective into the creation of an organized criminal group, where there is a similar incentive in matching on the probability of success. While the application is novel, it creates a niche to describe the process of forming a successful group and, thus, for law-enforcement to exploit matching frictions in reducing the crime rate.

\section{References}

National Incident-Based Reporting System. United States Department of Justice. Federal Bureau of Investigation, 1995-2010. Inter-university Consortium for Political and Social Research.

Abramitzky, Ran, Delavande, Adeline, \& Vasconcelos, Luis. 2011. Marrying Up: The Role of Sex Ratio in Assortative Matching. American Economic Journal: Applied Economics, 3(3), 124-57.

Aigner, Dennis J, \& Cain, Glen G. 1977. Statistical Theories of Discrimination in Labor Markets. Industrial and Labor Relations Review, 30(2), 175-187.

Alarid, Leanne Fiftal, Burton Jr, Velmer S, \& Hochstetler, Andy L. 2009. Group and Solo Robberies: Do Accomplices Shape Criminal Form? Journal of Criminal Justice, 37(1), 1-9.

Angrist, Josh. 2002. How Do Sex Ratios Affect Marriage and Labor Markets? Evidence from America's Second Generation. Quarterly Journal of Economics, 997-1038.

Arcand, Jean-Louis, \& Fafchamps, Marcel. 2012. Matching in CommunityBased Organizations. Journal of Development Economics, 98(2), 203-219.

Bagues, Manuel, \& Perez-Villadoniga, Maria J. 2012. Do recruiters prefer applicants with similar skills? Evidence from a randomized natural experiment. Journal of Economic Behavior \&3 Organization, 82(1), 12-20.

Becker, G. 1957. The Economics of Discrimination. 
Becker, G. 1973. A Theory of Marriage: Part I. The Journal of Political Economy, 81(4), 813-846.

Becker, G.S. 1968. Crime and Punishment: An Economic Approach. The Journal of Political Economy, 76(2), 169-217.

Borowczyk-Martins, Daniel, Bradley, Jake, \& Tarasonis, Linas. 2012. Assortative Matching, Search and Discrimination.

Dahl, Gordon, \& DellaVigna, Stefano. 2009. Does Movie Violence Increase Violent Crime? The Quarterly Journal of Economics, 124(2), 677-734.

Flabbi, Luca. 2010. Gender Discrimination Estimation in a Search Model with Matching and Bargaining. International Economic Review, 51(3), 745-783.

Lang, Kevin, \& Lehmann, Jee-Yeon K. 2012. Racial Discrimination in the Labor Market: Theory and Empirics. Journal of Economic Literature, 50(4), 1-48.

Levitt, Steven D, \& Miles, Thomas J. 2007. Empirical Study of Criminal Punishment. Handbook of Law and Economics, 1, 455-495.

Nakosteen, Robert A, Westerlund, Olle, \& Zimmer, Michael A. 2004. Marital Matching and Earnings: Evidence from the Unmarried Population in Sweden. Journal of Human Resources, 39(4).

Pencavel, John. 1998. Assortative Mating by Schooling and the Work Behavior of Wives and Husbands. American Economic Review, 88(2), 326-29.

Rose, E. 2007. A Joint Model of Marriage and Partner Choice. Tech. rept. University of Washington.

Shimer, Robert, \& Smith, Lones. 2003. Assortative Matching and Search. Econometrica, 68, 343-370.

Smith, Lones. 2006. The Marriage Model with Search Frictions. Journal of Political Economy, 114(6), 1124-1144.

Smith, Lones. 2011. Frictional Matching Models. Annual Review of Economics, 3, 319-338.

van Mastrigt, Sarah B, \& Carrington, Peter J. 2013. Sex and Age Homophily in Co-offending Networks: Opportunity or Preference? Crime and Networks. 
Table 3: Matching patterns

\begin{tabular}{|c|c|c|c|c|c|c|}
\hline & $\begin{array}{c}(1) \\
p^{1}-p^{2}\end{array}$ & $\begin{array}{c}(2) \\
p^{1}-p^{2}\end{array}$ & $\begin{array}{c}(3) \\
p^{1}-p^{2}\end{array}$ & $\begin{array}{c}(4) \\
p^{1}-p^{2}\end{array}$ & $\begin{array}{c}(5) \\
p^{1}-p^{2}\end{array}$ & $\begin{array}{c}(6) \\
p^{1}-p^{2}\end{array}$ \\
\hline White & $\begin{array}{c}-0.004^{* * *} \\
(0.001)\end{array}$ & $\begin{array}{c}-0.005^{* * *} \\
(0.001)\end{array}$ & $\begin{array}{c}-0.010 * * * \\
(0.003)\end{array}$ & $\begin{array}{c}-0.006^{* * *} \\
(0.001)\end{array}$ & $\begin{array}{c}-0.008^{* * *} \\
(0.003)\end{array}$ & $\begin{array}{c}-0.013^{* * *} \\
(0.004)\end{array}$ \\
\hline Female & $\begin{array}{c}0.007^{* * *} \\
(0.001)\end{array}$ & $\begin{array}{c}0.007^{* * *} \\
(0.001)\end{array}$ & $\begin{array}{c}0.017^{* * *} \\
(0.002)\end{array}$ & $\begin{array}{c}0.006^{* * *} \\
(0.001)\end{array}$ & $\begin{array}{c}0.002 \\
(0.001)\end{array}$ & $\begin{array}{c}0.012^{* * *} \\
(0.003)\end{array}$ \\
\hline Age & $\begin{array}{l}-0.000 \\
(0.000)\end{array}$ & $\begin{array}{l}-0.000 \\
(0.000)\end{array}$ & $\begin{array}{l}-0.000 \\
(0.000)\end{array}$ & $\begin{array}{l}-0.000 \\
(0.000)\end{array}$ & $\begin{array}{c}-0.000 * * \\
(0.000)\end{array}$ & $\begin{array}{l}-0.000 \\
(0.000)\end{array}$ \\
\hline $\log (\operatorname{loot})$ & & & & $\begin{array}{c}0.000 \\
(0.000)\end{array}$ & & \\
\hline Constant & $\begin{array}{l}-0.000 \\
(0.000)\end{array}$ & $\begin{array}{c}-0.000 * * * \\
(0.000)\end{array}$ & $\begin{array}{l}-0.001 \\
(0.001)\end{array}$ & $\begin{array}{l}-0.002 \\
(0.001)\end{array}$ & $\begin{array}{c}0.000 \\
(0.001)\end{array}$ & $\begin{array}{l}-0.001 \\
(0.001)\end{array}$ \\
\hline Observations & 928,636 & 928,636 & 422,377 & 847,121 & 187,617 & 239,547 \\
\hline R-squared & 0.000 & 0.020 & 0.000 & 0.000 & 0.000 & 0.000 \\
\hline $\begin{array}{l}\text { Year*Agency FE } \\
\text { Sample }\end{array}$ & - & $\mathrm{x}$ & $\begin{array}{c}- \\
\text { Only }\end{array}$ & - & - & - \\
\hline Restriction: & . & & Arrested & Loot & Age $\geq 30$ & $7<$ Hour $<20$ \\
\hline
\end{tabular}

Notes: Robust standard errors in parentheses. *** $\mathrm{p}<0.01, * * \mathrm{p}<0.05, * \mathrm{p}<0.1$. Errors clustered at the reporting agency level. The top of the column shows the dependent variable. Estimation through OLS, it includes interacted year and agency fixed effects where noted with " $\mathrm{x}$ ".

Table 4: Differences table

\begin{tabular}{lcccc} 
& Unconditional success means & \multicolumn{2}{c}{ Regression results } \\
Type of Couple & $p^{1} *$ & $p^{2}$ & $p^{1-p^{2}}$ & Standard Error \\
\hline Black Male-Black Male & 0.717 & 0.717 & & \\
Black Male-Black Female & 0.717 & 0.519 & $-0.007^{* * *}$ & 0.001 \\
Black Male-White Male & 0.717 & 0.600 & $0.005^{* * *}$ & 0.001 \\
Black Male-White Female & 0.717 & 0.508 & 0.003 & 0.002 \\
Black Female-Black Female & 0.518 & 0.519 & & \\
Black Female-White Male & 0.518 & 0.600 & $0.012^{* * *}$ & 0.002 \\
Black Female-White Female & 0.518 & 0.508 & $0.005^{* * *}$ & 0.001 \\
White Male-White Male & 0.600 & 0.600 & & \multirow{2}{*}{0.001} \\
White Male-White Female & 0.600 & 0.508 & $-0.007^{* * *}$ & \\
White Female-White Female & 0.507 & 0.508 & & \\
\hline
\end{tabular}

Notes: $p^{1} *$ and $p^{2} *$ denote the unconditional probabilities of success. $p^{1}$ and $p^{2}$ denote the probabilities of success, conditional on partner. "s.e." denotes the standard error for the mean of the difference $p^{1}-p^{2}$. 
Table 5: Robustness checks

\begin{tabular}{|c|c|c|c|c|c|c|}
\hline & $\begin{array}{c}(1) \\
p^{1}-p^{2}\end{array}$ & $\begin{array}{c}(2) \\
p^{1}-p^{2}\end{array}$ & $\begin{array}{c}(3) \\
p^{1}-p^{2}\end{array}$ & $\begin{array}{c}(4) \\
p^{1}-p^{2}\end{array}$ & $\begin{array}{c}(5) \\
p^{1}-p^{2}\end{array}$ & $\begin{array}{c}(6) \\
p^{1}-p^{2}\end{array}$ \\
\hline White & $\begin{array}{c}-0.004^{* * *} \\
(0.001)\end{array}$ & $\begin{array}{c}-0.004^{* * *} \\
(0.001)\end{array}$ & $\begin{array}{c}-0.004^{* * * *} \\
(0.001)\end{array}$ & $\begin{array}{c}-0.003^{* *} \\
(0.002)\end{array}$ & $\begin{array}{c}-0.004^{* * *} \\
(0.001)\end{array}$ & $\begin{array}{c}-0.005^{* * *} \\
(0.001)\end{array}$ \\
\hline Female & $\begin{array}{c}0.007^{* * *} \\
(0.001)\end{array}$ & $\begin{array}{c}0.007^{* * *} \\
(0.001)\end{array}$ & $\begin{array}{c}0.006^{* * *} \\
(0.001)\end{array}$ & $\begin{array}{c}0.006^{* * *} \\
(0.001)\end{array}$ & $\begin{array}{c}0.007^{* * *} \\
(0.001)\end{array}$ & $\begin{array}{c}0.007^{* * *} \\
(0.001)\end{array}$ \\
\hline Age & $\begin{array}{l}-0.000 \\
(0.000)\end{array}$ & $\begin{array}{c}0.000 \\
(0.000)\end{array}$ & $\begin{array}{l}-0.000 \\
(0.000)\end{array}$ & $\begin{array}{c}-0.002^{* * * *} \\
(0.001)\end{array}$ & $\begin{array}{l}-0.000 \\
(0.000)\end{array}$ & $\begin{array}{l}-0.000 \\
(0.000)\end{array}$ \\
\hline Gang & $\begin{array}{c}-0.006^{* *} \\
(0.003)\end{array}$ & & & & & \\
\hline Indian Race & & $\begin{array}{c}-0.004 \\
(0.006)\end{array}$ & & & & \\
\hline Asian Race & & $\begin{array}{c}0.001 \\
(0.006)\end{array}$ & & & & \\
\hline Constant & $\begin{array}{l}-0.000 \\
(0.000)\end{array}$ & $\begin{array}{l}-0.000 \\
(0.000)\end{array}$ & $\begin{array}{c}-0.001^{*} \\
(0.000)\end{array}$ & $\begin{array}{l}-0.000 \\
(0.000)\end{array}$ & $\begin{array}{l}-0.000 \\
(0.000)\end{array}$ & $\begin{array}{c}-0.000^{* * *} \\
(0.000)\end{array}$ \\
\hline Observations & 928,636 & 945,176 & 787,282 & 648,279 & 924,137 & 928,636 \\
\hline R-squared & 0.000 & 0.000 & 0.000 & 0.000 & 0.000 & 0.017 \\
\hline Year*Agency & - & - & - & - & - & \\
\hline Year*City & & & & & & $\mathrm{x}$ \\
\hline Sample & & & Same & & Agency & \\
\hline Restriction: & & & Offense & Age Gap $<5$ & index $\in(0,1)$ & \\
\hline
\end{tabular}

Notes: Robust standard errors in parentheses. $* * * \mathrm{p}<0.01,{ }^{* *} \mathrm{p}<0.05, * \mathrm{p}<0.1$. Errors clustered at the reporting agency level. The top of the column shows the dependent variable. Estimation includes interacted year agency fixed effects where noted. In column 5 the sample includes agencies that are heterogeneous in at least one dimension between gender and race. Column 6 includes interacted year city fixed effects instead of year-agency. 
Table 6: Results by Crime Type

\begin{tabular}{llccccccccccc}
\hline UCR Code & Crime & White & \multicolumn{3}{c}{ Female } & Age & & Constant & & Observations & R-squared \\
\hline 200 & Arson & -0.021 & $(0.022)$ & 0.017 & $(0.013)$ & 0.001 & $(0.001)$ & $0.011^{*}$ & $(0.006)$ & 4,337 & 0.001 \\
231 & Pocket-picking & -0.001 & $(0.022)$ & 0.006 & $(0.011)$ & 0.001 & $(0.001)$ & 0.006 & $(0.006)$ & 1,790 & 0.001 \\
232 & Purse-snatching & 0.004 & $(0.017)$ & -0.007 & $(0.011)$ & -0.002 & $(0.001)$ & -0.000 & $(0.006)$ & 2,863 & 0.001 \\
233 & Shoplifting & $-0.009^{* * *}$ & $(0.003)$ & $-0.003^{*}$ & $(0.002)$ & $-0.001^{* * *}$ & $(0.000)$ & -0.001 & $(0.001)$ & 260,302 & 0.000 \\
234 & Theft from Building & $-0.011^{* *}$ & $(0.004)$ & 0.002 & $(0.002)$ & $0.000^{*}$ & $(0.000)$ & 0.001 & $(0.001)$ & 66,485 & 0.000 \\
235 & Theft from Coin-Operated Machine & -0.073 & $(0.045)$ & 0.066 & $(0.041)$ & -0.001 & $(0.001)$ & 0.002 & $(0.006)$ & 2,499 & 0.013 \\
236 & Theft from/of Motor Vehicle & 0.003 & $(0.006)$ & $0.019^{* * *}$ & $(0.004)$ & $0.001^{* * *}$ & $(0.000)$ & $-0.003^{* *}$ & $(0.001)$ & 53,866 & 0.001 \\
237 & Parts & -0.009 & $(0.011)$ & $0.031^{* * *}$ & $(0.010)$ & -0.000 & $(0.001)$ & 0.000 & $(0.003)$ & 12,464 & 0.001 \\
238 & All Other Larceny & $-0.005^{*}$ & $(0.003)$ & $0.005^{* * *}$ & $(0.001)$ & $0.000^{* * *}$ & $(0.000)$ & -0.000 & $(0.001)$ & 166,734 & 0.000 \\
240 & Motor Vehicle Theft & $0.013^{*}$ & $(0.007)$ & $0.026^{* *}$ & $(0.004)$ & $0.001^{* * *}$ & $(0.000)$ & 0.001 & $(0.002)$ & 47,494 & 0.002 \\
220 & Burglary & -0.003 & $(0.003)$ & $0.017^{* * *}$ & $(0.002)$ & -0.000 & $(0.000)$ & -0.001 & $(0.001)$ & 142,193 & 0.001 \\
120 & Robbery & $-0.008^{* *}$ & $(0.003)$ & $0.019^{* * *}$ & $(0.004)$ & $-0.0011^{* * *}$ & $(0.000)$ & -0.000 & $(0.001)$ & 101,160 & 0.001 \\
280 & Stolen Property Offenses & 0.013 & $(0.010)$ & $0.019^{* * *}$ & $(0.005)$ & $0.001^{* *}$ & $(0.000)$ & -0.001 & $(0.003)$ & 15,003 & 0.001 \\
\hline
\end{tabular}




\section{A Specification}

The regression specification in the main text is:

$$
p^{1}-p^{2}=\alpha+\beta_{w}\left(W^{1}-W^{2}\right)+\beta_{f}\left(F^{1}-F^{2}\right)+\beta_{a}\left(A^{1}-A^{2}\right)+\epsilon
$$

where 1 and 2 refer to the order of the criminals in the partnership. $W$ is an indicator variable for skin colour, $\mathrm{F}$ is an indicator variable for the female gender. $\mathrm{A}$ is age, measured in years. The outcome variable $p^{1}-p^{2} \in\{-1,0,1\}$. The first 2 columns of table A.1 repeat the results from table 3 from the main text. The first column shows the baseline results with no fixed effects, the second with fixed effects. The last 2 columns show the estimation results for a multinomial logit model with base outcome 0 and no fixed effects,. The results are in line with the ones in the first 2 columns and the marginal effect follow the pattern of the signs of the coefficients in OLS. For e.g. the marginal effect for white is positive $(.0025)$ for the relative outcome of $p^{2}>p^{1}$ with respect to $p^{2}=p^{1}$. Therefore, in the situation of the first criminal becoming white (very hypothetical), while the second is black, there is an increased likelihood that $p^{2}>p^{1}$.

The alternative specification considered in this section is:

$$
p^{1}-p^{2}=\alpha+\beta_{w}^{1} W^{1}+\beta_{w}^{2} W^{2}+\beta_{f}^{1} F^{1}+\beta_{f}^{2} F^{2}+\beta_{a}^{1} A^{1}+\beta_{a}^{2} A^{2}+\epsilon
$$

where $\beta^{1}=-\beta^{2}$ by construction. This symmetry condition is sensitive to the random order of criminals within a couple. However, when taking several random orders and taking the mean estimates, it seems that the mean estimate for white is 0.004 and for female 0.007 , both significant. Table A.2 presents the results. The first column shows estimates with no fixed effects and column 2 shows that the point estimates do not change with the inclusion of location-year specific fixed effects.

Considering a black male and female couple, the dependent variable becomes negative, showing that the probability of success of the female is higher than that of the male. Similarly, in a male white and black couple the probability of success of the white criminal is lower than that of the black. These results are in line with the results in the main text. The last 2 columns show the estimation results for a multinomial logit model. They are in line with the results in the previous column. For e.g. the marginal effect for the variable White 2 for a positive outcome variable is positive $(0.003)$. When the second person in the pair is white it is more likely that the probability of success of the first black male is bigger than the probability of success of the second white male. The marginal effect for the second criminal to be a female is -0.005 . Only the variable for age seems to show different results than in the previous specifications, the marginal effect for age of both criminals is positive ( .00018 to .00022) for both relative outcomes.

\section{B Further Robustness Checks}


Table A.1: Multinomial Logit Estimates

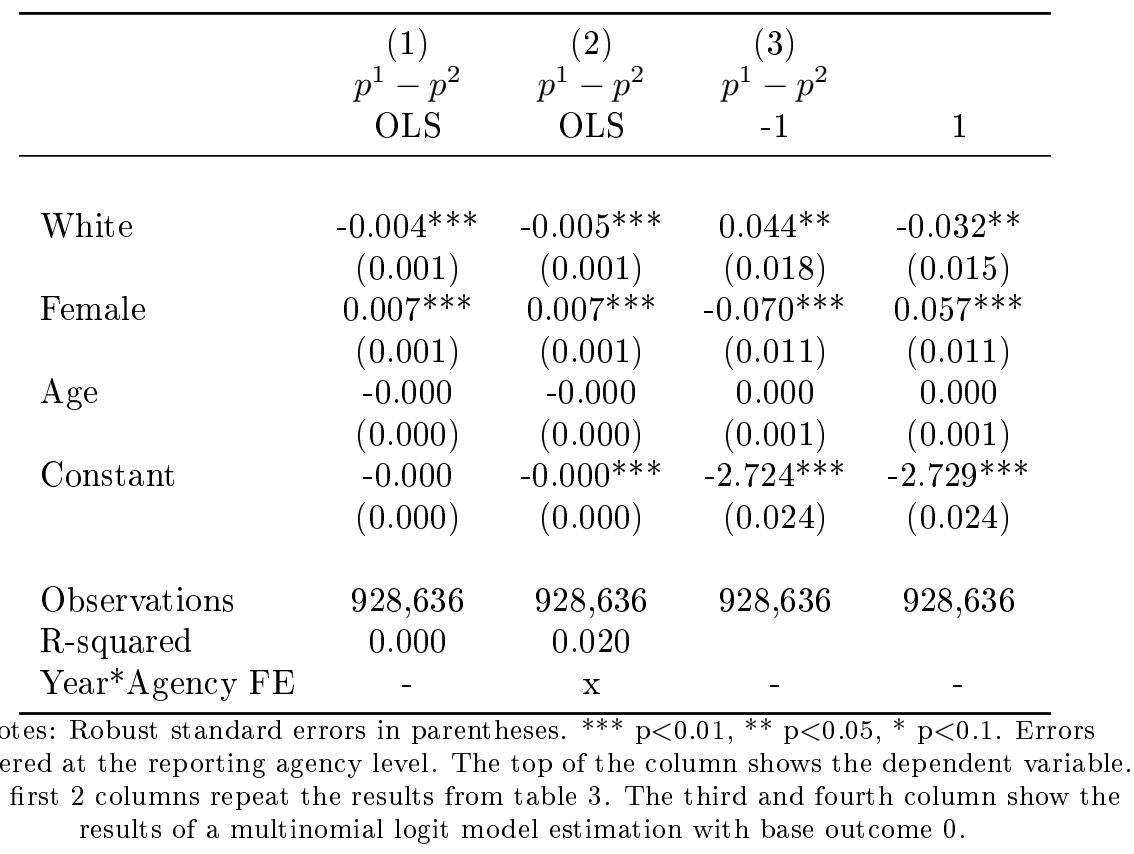


Table A.2: Results with a Different Specification

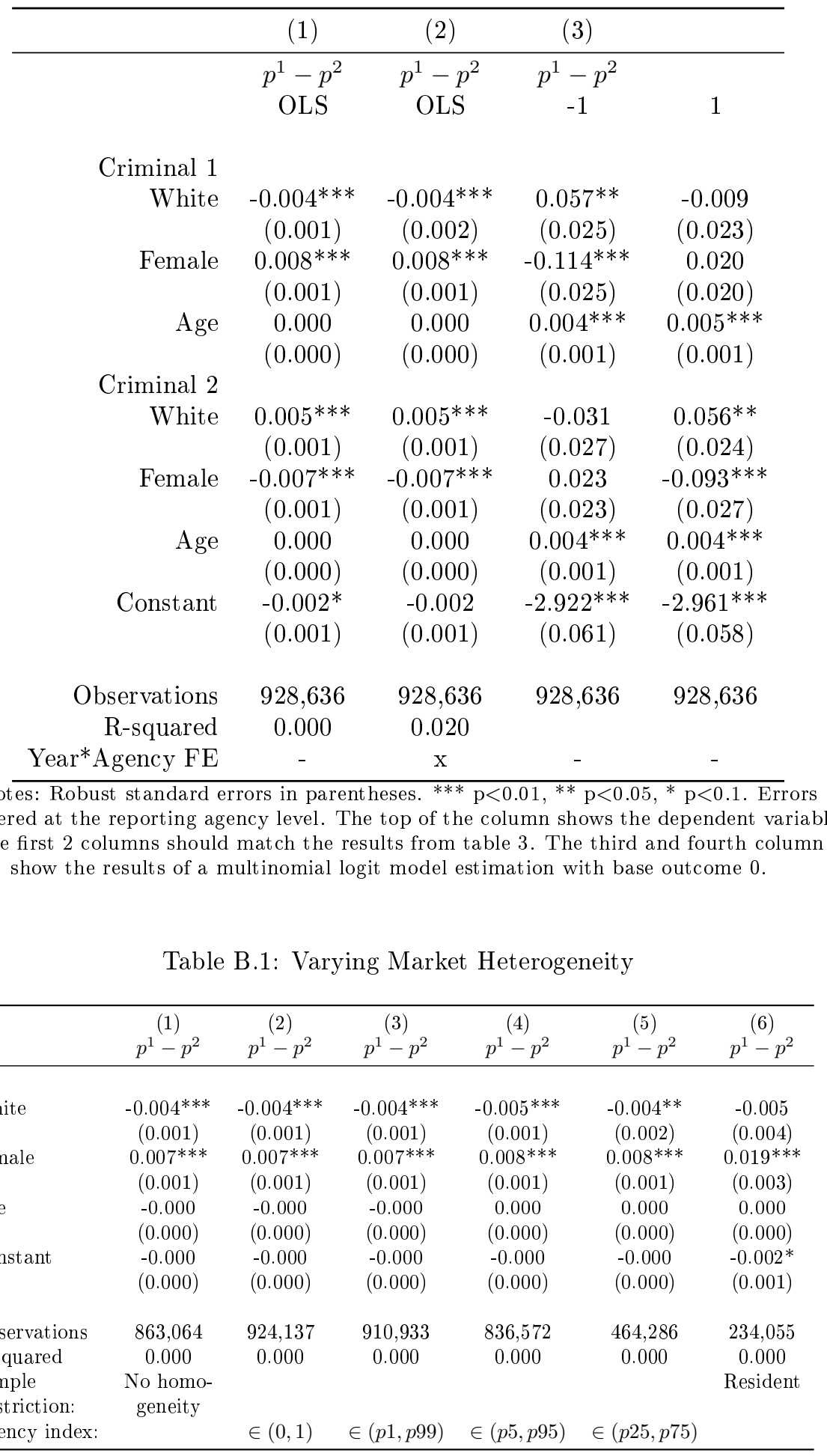


Table B.2: Varying Ages

\begin{tabular}{|c|c|c|c|c|c|c|}
\hline & $\begin{array}{c}(1) \\
p^{1}-p^{2}\end{array}$ & $\begin{array}{c}(2) \\
p^{1}-p^{2}\end{array}$ & $\begin{array}{c}(3) \\
p^{1}-p^{2}\end{array}$ & $\begin{array}{c}(4) \\
p^{1}-p^{2}\end{array}$ & $\begin{array}{c}(5) \\
p^{1}-p^{2}\end{array}$ & $\begin{array}{c}(6) \\
p^{1}-p^{2}\end{array}$ \\
\hline White & $\begin{array}{c}-0.003^{* *} \\
(0.002)\end{array}$ & $\begin{array}{c}-0.003^{*} \\
(0.002)\end{array}$ & $\begin{array}{c}-0.004^{* *} \\
(0.002)\end{array}$ & $\begin{array}{c}-0.003^{*} \\
(0.002)\end{array}$ & $\begin{array}{c}-0.006^{* * *} \\
(0.002)\end{array}$ & $\begin{array}{c}-0.004^{* * *} \\
(0.001)\end{array}$ \\
\hline Female & $\begin{array}{c}0.006^{* * *} \\
(0.001)\end{array}$ & $\begin{array}{c}0.007^{* * *} \\
(0.001)\end{array}$ & $\begin{array}{c}0.007^{* * *} \\
(0.001)\end{array}$ & $\begin{array}{c}0.008^{* * *} \\
(0.001)\end{array}$ & $\begin{array}{c}0.006^{* * *} \\
(0.001)\end{array}$ & $\begin{array}{c}0.007^{* * *} \\
(0.001)\end{array}$ \\
\hline Age & $\begin{array}{c}-0.002^{* * *} \\
(0.001)\end{array}$ & $\begin{array}{c}-0.003^{* * *} \\
(0.001)\end{array}$ & $\begin{array}{c}-0.005^{* * *} \\
(0.001)\end{array}$ & $\begin{array}{c}-0.007^{* * *} \\
(0.001)\end{array}$ & & \\
\hline Constant & $\begin{array}{l}-0.000 \\
(0.000)\end{array}$ & $\begin{array}{l}-0.000 \\
(0.000)\end{array}$ & $\begin{array}{l}-0.000 \\
(0.000)\end{array}$ & $\begin{array}{l}-0.000 \\
(0.000)\end{array}$ & $\begin{array}{c}-0.000 \\
(0.001)\end{array}$ & $\begin{array}{l}-0.000 \\
(0.000)\end{array}$ \\
\hline Observations & 648,279 & 599,359 & 530,101 & 427,588 & 262,757 & 928,636 \\
\hline R-squared & 0.000 & 0.000 & 0.000 & 0.000 & 0.000 & 0.000 \\
\hline Sample Restriction: & Age Gap $<5$ & 4 & 3 & 2 & 1 & Age Dummies \\
\hline
\end{tabular}

